\title{
Get on board: Assessing an all-door boarding pilot project in Montreal, Canada
}

\author{
Ahmed El-Geneidy, \\ Dea van Lierop, \\ Emily Grisé, \\ Geneviève Boisjoly, \\ Derrick Swallow, \\ Lesley Fordham \& \\ Thomas Herrmann
}

McGill University: School of Urban Planning

Suite 400, 815 Sherbrooke St. W.

Montréal, Québec, H3A 2K6

Canada

Tel.: 514-398-4058

Fax: 514-398-8376

E-mail: ahmed.elgeneidy@mcgill.ca

For Citation Please use: El-Geneidy, A., van Lierop, D., Grisé, E., Boisjoly, G., Swallow, D., Fordham, L., \& Herrmann, T. (2017). Get on board: Assessing an all-door boarding pilot project in Montreal, Canada. Transportation Research Part A: Policy and Practice, 99, 114-124. 


\begin{abstract}
Transit agencies often focus on developing strategies aimed at reducing travel time to increase passengers' satisfaction. One strategy used by transit agencies to reduce passenger activity time, and accordingly travel times, is the implementation of all-door boarding - a service allowing transit users to board and alight vehicles through any door. The present study uses data collected in Montreal, Canada, to assess the impacts of an all-door boarding pilot project from two points of view: (1) operationally through passenger activity time, and (2) by assessing passenger satisfaction. Operationally, the results reveal that when compared to a similar bus route that does not allow all-door boarding, the all-door boarding strategy shows a savings of five percent in passenger activity time at regular stops, while time savings at high passenger activity stops such as metro stations experienced time savings of around 19 percent. Thus, savings are maximized at stops with high passenger demand. Additionally, with regard to user perceptions, the results reveal that passengers who use the all-door boarding service are more satisfied with bus service, particularly with on time performance. Overall, the results of this study demonstrate that all-door boarding is an effective strategy to improve the quality of service due to the associated time savings and increased customer satisfaction. Finally, the study offers important recommendations to transit planners and policy makers to effectively implement and maximize the benefits of an all-door boarding policy based on statistical analysis and on-site observations.
\end{abstract}




\section{INTRODUCTION}

Transit agencies often focus on developing strategies aimed at increasing ridership by attracting new passengers and retaining existing ones. One way to increase overall ridership is by focusing on how to keep existing passengers satisfied with the system. Accordingly, because it has been well-documented that overall travel time and speed influence transit users' level of satisfaction with the overall service (dell'Olio, Ibeas, \& Cecín, 2011; Mouwen, 2015), transit agencies are constantly looking to implement strategies that improve transit users' actual and perceived satisfaction with overall travel time and speed. One such strategy is to decrease transit users' boarding and alighting times.

In most countries, where the bus driver is the only transit employee on-board, passengers board at the front of the vehicle, through a single door, so they can interact with and purchase tickets from the driver. Today, one-door boarding continues to be popular throughout the world, even though researchers have found that it is not the most efficient way for users to board vehicles as it is associated with slow overall boarding times (Jara-Diaz \& Tirachini, 2013; C. Stewart \& ElGeneidy, 2014; Tirachini, Camus, \& Cruz, 2016). In contrast, all-door boarding is a strategy that allows passengers to board through any of the bus doors. This strategy allows for multiple flows of passengers boarding at the same time, leading to an expedited boarding process that can decrease overall travel times and improve route efficiency (Larwin \& Koprowski, 2012). Furthermore, although the reductions are in passenger activity per door, they can be reflected by reductions in overall running time. This can be economically beneficial for transit agencies, particularly if the time savings are sufficient enough to reduce the number of buses serving a route while providing the same frequency of service (C. Stewart \& El-Geneidy, 2014).

Reducing bus running time is therefore beneficial for both improving the efficiency of the bus system (Levine \& Torng, 1994), and for increasing overall user satisfaction. However, most research has focused solely on analyzing improvements to the efficiency of routes, and few studies have assessed riders' perceptions and levels of satisfaction with a particular bus operation improvement strategy (Diab \& El-Geneidy, 2012a). With this in mind, the purpose of this paper is to assess the impacts of an all-door boarding pilot project in Montreal, Canada from two points of view: (1) operationally through passenger activity time, and (2) by assessing passenger satisfaction. We combine operations and customer satisfaction data with the intention of understanding how operational strategies affect customers' perceptions of service. Furthermore, 
this study can be helpful to researchers and transit agencies wishing to better understand the impacts of all-door boarding policies, and provides insights on implementation strategies of such policies.

This study begins with a review of the relevant literature of all-door boarding and customer satisfaction. Next, in the first phase of the analysis, we use manually collected operations data to estimate time savings from all-door boarding. In the second phase, we use data derived from customer satisfaction questionnaires to evaluate bus passenger satisfaction with the new service as well as their perceptions pertaining to changes in travel times. The next phase of the analysis concentrates on observations made by the authors during the data collection process. Finally, based on the field observations as well as the results of the statistical analyses, the paper concludes with a discussion of strategies which can be implemented to achieve the maximum benefits from an alldoor boarding service.

\section{LITERATURE REVIEW}

\section{All-Door Boarding}

Dwell time is a major factor affecting the running time of a bus and is defined as the time spent at a bus stop to service passengers - from door open to door close (Dueker, Kimpel, Strathman, \& Callas, 2004; El-Geneidy \& Vijayakumar, 2011). According to Levinson (1983), dwell time generally accounts for 9 to 26 percent of the total running time of a bus route. Accordingly, significant running time savings can be achieved through a reduction in dwell times (Abkowitz \& Engelstein, 1982). Passenger activity time, the time consumed by all passengers to board and alight from a bus, is the main contributor to dwell time. While passenger activity times are shorter than overall dwell times, they are highly correlated (Cundill \& Watts, 1973; Levine \& Torng, 1994; Vandebona \& Richardson, 1985). However, when a bus arrives at a time point early, dwell time, door open to door close, is usually considerably longer than passenger activity time. This is because the driver will wait at the bus stop with the door open after passenger activity has ended and before it is time to depart from the stop. Such additional time is known as excess dwell. Excess dwell time can lead to a bias in dwell time models showing higher boarding and alighting times per passenger. Accordingly, to carefully study the impacts of any improvement strategy, a detailed analysis of passenger activity time is needed to avoid any bias imposed from excess dwell time. 
One way to reduce dwell times (and associated passenger activity times) is by implementing an all-door boarding strategy as it leads to shorter boarding times at bus stops (Larwin \& Koprowski, 2012). Three main aspects explain the shorter passenger activity time that results from multiple-door boarding. The first is that multiple streams of passengers can board the bus at the same time, thus reducing the number of passengers boarding at the front door. The second is that all-door boarding results in a more balanced distribution of passengers in the bus and accordingly, reduces the crowding at each door. Passenger friction, which is contingent on the crowding at each door, has been shown to increase passenger activity time (Sun, Tirachini, Axhausen, Erath, \& Lee, 2014). When crowding is reduced at the doors, especially the front door, boarding time per passenger is significantly reduced, by up to 0.5 seconds (Larwin \& Koprowski, 2012). Another study, based on real-scale experiments, also found a negative, linear relationship between crowding and boarding time (Fernandez, 2011). Interestingly, crowding was found to exponentially affect alighting time. Finally, in some cases, all-door boarding provides passengers waiting at a bus stop with a closer boarding option than the front door, which reduces the boarding time (Jaiswal, Bunker, \& Ferreira, 2010). Overall, multiple-door boarding thus reduces the amount of time spent at a bus stop, as a function of passenger activity. However, the relationship between stop time and passenger activity is non-linear, indicating that each additional passenger requires less time to board than the passenger ahead, and a passenger activity squared term accurately captures this relationship (Dueker et al., 2004; El-Geneidy \& Vijayakumar, 2011; Rajbhandari, Chien, \& Daniel, 2003).

With regard to time savings, all-door boarding strategies implemented on articulated buses with three doors can result in running time savings of between 4.6 and 13.3 percent (Larwin \& Koprowski, 2012). In the case of Montreal, C. Stewart and El-Geneidy (2014) estimated time savings of up to 15.9 percent during morning peak hours along some routes that use articulated buses. Alternatively, in the case of two-door boarding systems, running time savings of 1.8 to 9.6 percent are estimated (Larwin \& Koprowski, 2012).

A concern related to the implementation of all-door boarding systems is fare evasion. If passengers boarding at the back doors are not validating their ticket or pass, and if the bus includes a validation machine, ticket validation is left to an honor system. Yet, several studies have found that actual fare evasion rates are much lower than what is perceived (Larwin \& Koprowski, 2012; Lee, 2011). For example, Ottawa and San Francisco use all-door boarding systems and have 
relatively low to average evasion rates at only 2.4 percent and 4.7 percent respectively. In comparison, Bonfanti and Wagenknecht (2010) found an average of 4.2 percent reported fare evasion in a large sample of 31 bus routes in 18 countries. Although it is highly improbable to completely eliminate fare evasion on all-door boarding systems, evasion rates can be controlled by hiring more fare inspectors or through the use of turnstiles.

\section{Operations data}

The emergence of intelligent transport system technologies has allowed in-depth research on bus operations, including dwell time models (Berkow, El-Geneidy, Bertini, \& Crout, 2009), which are heavily used in the literature to evaluate different operational improvement strategies. Determinants of dwell times have been found to include passenger activity (boardings and alightings), passenger load, lift/ramp usage for disabled persons, the use of bicycle racks, delay, time of day, and weather conditions (Abkowitz \& Engelstein, 1982; Levinson, 1983; Rajbhandari et al., 2003; Strathman et al., 2000). Most recent bus operations models use archived automaticvehicle-location (AVL) and automatic-passenger-counter (APC) systems data (El-Geneidy, Strathman, Kimpel, \& Crout, 2006; Gibson, Munizaga, Schneider, \& Tirachini, 2015; Kimpel, 2001; Kimpel, Strathman, Bertini, Bender, \& Callas, 2005; Milkovits, 2008) to predict running times and dwell times (Dueker et al., 2004; El-Geneidy \& Vijayakumar, 2011). The dwell time used in these models is automatically collected (from door opening to door closing). Using dwell times, however, does not directly capture the passenger activity time, because it also includes excess dwell time, and accordingly does not capture the full impact of any improvement strategy such as all-door boarding. Sun et al. (2014) used smart card data to assess the influence of passenger friction on passenger activity time for various bus types, but did not include all-door boarding buses in their analysis. Also, for a tap-on tap-off system, using fare payment data to determine the beginning and end of passenger activity time ignores the time used by the first passenger boarding and the last passenger alighting the bus. Similarly, for a system that requires only tap-on, smart card data cannot be used to determine the end of passenger activity time. To our knowledge, no study has assessed the influence of all-door boarding on actual passenger activity time in such detail.

\section{Passenger Satisfaction}


In addition to the time savings benefits, all-door boarding potentially leads to improved passenger satisfaction (Walker, 2012). Shorter running times generally reduce the in-vehicle time for passengers, and reduced travel times are seen positively by passengers (Diab \& El-Geneidy, 2012b). Furthermore, since passengers are boarding at all doors, the distribution of passengers in the bus is expected to be more balanced, which might result in less crowding.

Since perception does not always reflect the reality of operations (Diab \& El-Geneidy, 2014), it is essential to assess how passengers perceive service changes. This is important because changes in operations may be over or underestimated by passengers and influence their satisfaction accordingly. For example, in a previous study, Diab and El-Geneidy (2014) found that passengers perceived more reductions in travel times compared to reality after the implementation of a combination of bus operations strategies. Given the discrepancies between bus operations and passengers' satisfaction, the present study examines the impact of all-door boarding policy both on passenger activity time and on passenger satisfaction.

\section{STUDY CONTEXT}

To assess the impact of all-door boarding, this study focuses on analyzing manually collected data from route 121 Sauvé, a major east-west route along Côte-Vertu Boulevard and Sauvé Street, in Montreal, Quebec, Canada. Route 121 is operated by the Société de transport de Montréal (STM), which is the primary transit operator in Montreal. The route serves 52 stops (11.5 kilometers) on westbound journeys and 48 stops (11.1 kilometers) eastbound. Route 121 is a regular, non-express bus service, with stops spaced every few city blocks, and an average one-way trip duration of 50.5 minutes. The route is characterized by a high frequency of service, with headways averaging 7.5 minutes. Approximately 34,000 trips are made on the route every weekday, making it one of the busiest in the network. Route 121 provides connections to two metro stations (Côte-Vertu and Sauvé) and two commuter rail stations (Montpellier and Sauvé).

On March 21st, 2016, the STM introduced a pilot all-door boarding policy along route 121

as it was identified by a previous study as one of the routes with high potential for time savings if all-door boarding were to be implemented (C. Stewart \& El-Geneidy, 2014). The policy permits passengers with an unlimited use pass (weekly or monthly) to board the bus through the front, middle, or back doors. Previously, boarding was restricted to the front door to validate passes. While passengers boarding through the back doors are not required to prove that they have a valid 
ticket, those boarding through the front must use the tap-on system, even if they hold an unlimited use pass. All-door boarding policies are increasingly being implemented by other transit agencies in Canada and elsewhere, and are identified as a best practice for heavily used bus routes (Levinson, Zimmerman, Clinger, \& Rutherford, 2002; A. Stewart, Attanucci, \& Wilson, 2015). Front-door-only boarding remains the standard policy for all other bus routes operated by the STM.

In addition to route 121, data was collected for route 69 Gouin, which is also operated by the STM. Route 69 does not allow all-door boarding, and was selected as a control route because it runs roughly parallel to route 121 . The two routes are also similar in several other operational characteristics, such as similar average stop spacing, operation in neighborhoods with comparable built environments, and both routes share a connection with a metro station. Furthermore, both bus routes exclusively operate articulated buses. Figure 1 shows a context map of both routes studied.
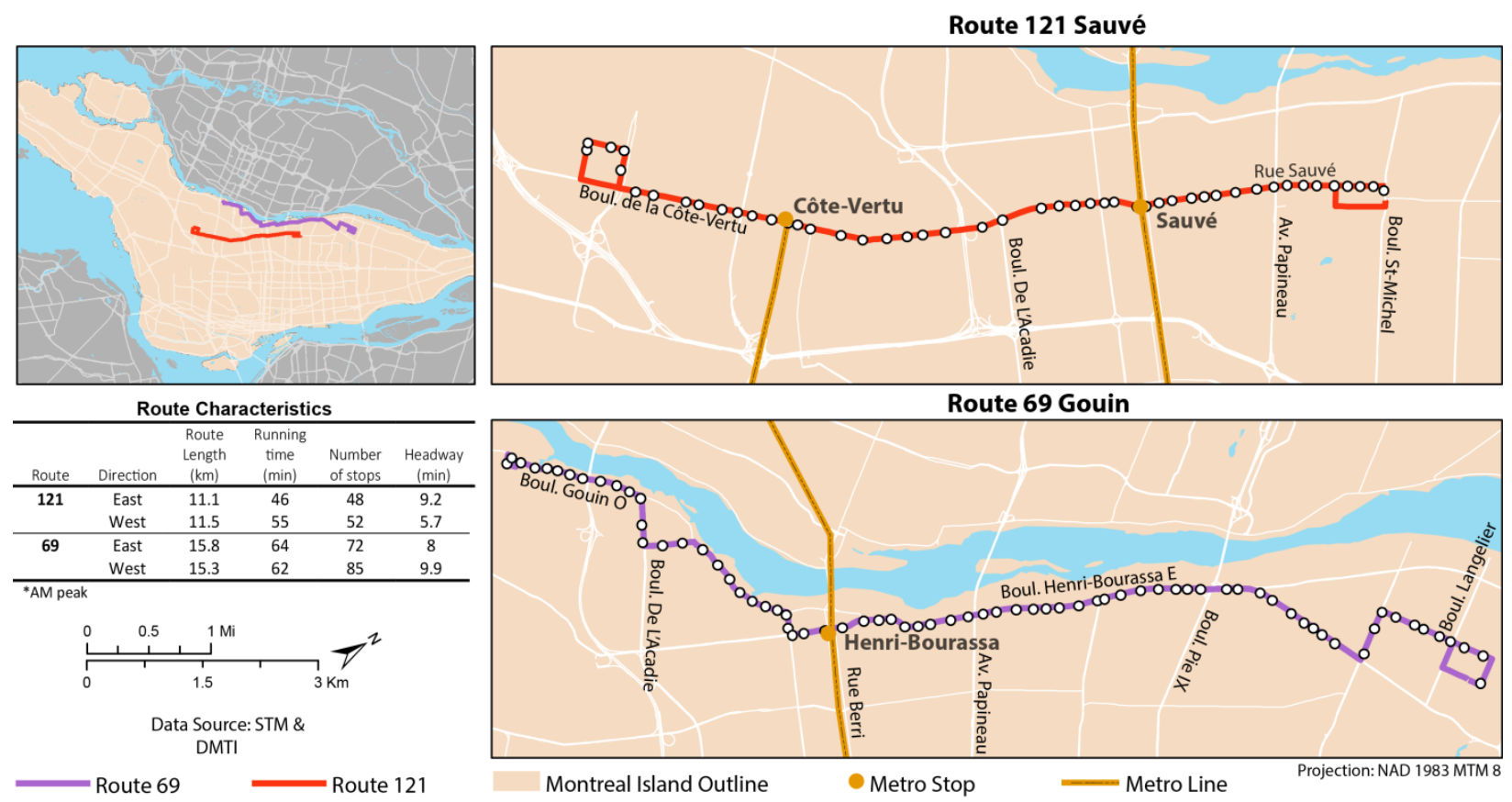

Route $69 \quad$ Route 121

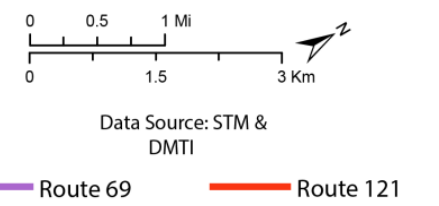

FIGURE 1. Context map of routes studied and relevant route characteristics

\section{ANALYSIS OF OPERATIONS}

The first objective of this study is to understand the impacts of all-door boarding on passenger activity time. Accordingly, we analyze the effects of all-door boarding on route 121, through a comparison of passenger activity time between route 121 and route 69 , which does not allow alldoor boarding. 


\section{Collection of operations data}

The operations data used in this analysis were collected through field measurement, with three individuals collecting data related to the passenger activity at each stop along both routes. The specific information collected at each stop included: the per door passenger boardings and alightings at each stop, the time of passenger activity, arrival time at each stop, payment type, as well as observations related to passenger encumberment (such as a stroller, or large, heavy bags), and whether passengers had an observable disability or mobility restriction which may have extended the average time of passenger activity. The passenger activity time was calculated from the end of front door opening until the moment that the last passenger had fully entered the bus or alighted from the bus. A total of 1,036 stop observations were collected from 17 unique trips aboard route 121 and, additionally, data from four unique trips was collected from route 69. Moreover, during the data collection it was observed that the majority of passenger boardings occurred through the front door. In fact, at stops where the all-door policy could have had the greatest positive impact, specifically at stops where three or more passenger boarded, $88 \%$ of users boarded at the front door. This suggests that the new boarding policy may not have been adequately communicated during the pilot project.

Data collection occurred between 6:30 AM and 6:30 PM on a Tuesday, Wednesday, and Thursday early in the summer of 2016. The dates and times of data collection were chosen to collect an equal distribution of data between peak and off-peak hours. Throughout the data collection, weather conditions were normal (dry) and no events impeded ordinary operations of the bus route.

\section{Passenger Activity Model}

A passenger activity model was constructed to measure the effects of all-door boarding on the average time of passenger activity. Characteristics of each bus stop were collected and tested in the model, such as stops occurring on the near-side or far-side of an intersection, presence of a reserved bus lane, and bus shelters. However, few were found significant and included in the final model. Additionally, time of day was tested in the model, but did not show statistical significance and was not included in the final model. Since the objective of this analysis is to estimate the time savings of all-door boarding, variables related to passenger activity in the model include: total boardings and alightings, passenger load, a passenger friction factor, passenger activity squared, 
and a dummy variable of whether an encumbered passenger was boarding or alighting the stop. Finally, two interactive terms were included in the model to test the effect of passenger boardings that occurred at a bus stop with all-door boarding on passenger activity time and the effect of passenger boardings at a bus stop that served a metro station. Table 1 presents the descriptive statistics of the variables included in the passenger activity time model.

TABLE 1. Descriptive statistics of passenger activity time model variables

\begin{tabular}{|c|c|c|c|}
\hline Variable Name & Description & Mean & $\begin{array}{l}\text { Std. } \\
\text { Dev. }\end{array}$ \\
\hline Total Boardings & $\begin{array}{l}\text { Total number of passengers that boarded at all doors } \\
\text { at a single bus stop during a trip. }\end{array}$ & 2.20 & 5.27 \\
\hline Total Alightings & $\begin{array}{l}\text { Total number of passengers that alighted at all doors } \\
\text { at a single bus stop during a trip. }\end{array}$ & 2.43 & 5.84 \\
\hline $\begin{array}{l}\text { Total Passenger } \\
\text { Activity } \wedge 2\end{array}$ & $\begin{array}{l}\text { The square of the total number of passenger } \\
\text { boardings and alightings at all doors at a stop during } \\
\text { a trip. }\end{array}$ & 121.93 & 756.16 \\
\hline Route 121 & $\begin{array}{l}\text { A dummy variable equal to } 1 \text { if the stop occurs on } \\
\text { route } 121 \text {. }\end{array}$ & 0.77 & 0.42 \\
\hline Friction & $\begin{array}{l}\text { The total number of standees within one square meter } \\
\text { of each door plus the sum of the total boardings and } \\
\text { alightings at a stop. }\end{array}$ & 5.13 & 10.77 \\
\hline Passenger Load & $\begin{array}{l}\text { The total number of passengers on a bus at the } \\
\text { departure of a stop. }\end{array}$ & 27.28 & 16.04 \\
\hline Eastbound Trip & $\begin{array}{l}\text { A dummy variable equal to } 1 \text { if the stop occurs on an } \\
\text { eastbound trip. }\end{array}$ & 0.49 & 0.50 \\
\hline Metro Station & $\begin{array}{l}\text { A dummy variable equal to } 1 \text { if the stop occurs at a } \\
\text { metro station. }\end{array}$ & 0.05 & 0.22 \\
\hline $\begin{array}{l}\text { Encumbered } \\
\text { Passenger }\end{array}$ & $\begin{array}{l}\text { A dummy variable equal to } 1 \text { if a passenger with an } \\
\text { encumberment, disability or mobility limitation } \\
\text { boarded or alighted the bus. }\end{array}$ & 0.03 & 0.18 \\
\hline $\begin{array}{l}\text { Signalized } \\
\text { intersection }\end{array}$ & $\begin{array}{l}\text { A dummy variable equal to } 1 \text { if the stop occurs at a } \\
\text { signalized intersection. }\end{array}$ & 0.66 & 0.47 \\
\hline $\begin{array}{l}\text { Total } \\
\text { Boardings*Route } 121\end{array}$ & $\begin{array}{l}\text { An interactive term of the number of passengers } \\
\text { boarding a bus at all stops along route } 121 \text {. }\end{array}$ & NA & NA \\
\hline $\begin{array}{l}\text { Total } \\
\text { Boardings*Metro } \\
\text { Station }\end{array}$ & $\begin{array}{l}\text { An interactive term of the number of passengers } \\
\text { boarding a bus at all doors at a metro stop. }\end{array}$ & NA & NA \\
\hline
\end{tabular}

Linear regression was used to model passenger activity time as the dependent variable, with a series of independent variables meant to capture the variation in passenger activity time between bus routes 121 and 69. After removing layover stops (the first and final stops of each trip) 
and incomplete records, 986 stop-level observations were analyzed in the passenger activity time model. The variables included in the final model explain approximately 73 percent of the variation in passenger activity time, and the model results are presented in Table 2.

TABLE 2. Passenger activity time model

\begin{tabular}{llllc}
\hline & Estimate & t-statistic & \multicolumn{2}{l}{$95 \%$ Conf. intervals } \\
\cline { 2 - 5 } Constant & $1.77 * * *$ & 2.69 & 0.48 & 3.07 \\
Total Boardings & $3.24 * * *$ & 15.75 & 2.84 & 3.64 \\
Total Alightings & $1.07 * * *$ & 9.98 & 0.86 & 1.28 \\
Total Passenger Activity ${ }^{\wedge} 2$ & $-0.005 * * *$ & -7.33 & -0.01 & 0.00 \\
Friction & $-0.16^{*}$ & -1.77 & 0.26 & 2.49 \\
Passenger Load & $0.030^{*}$ & 1.90 & 0.00 & 0.06 \\
Route 121 & $1.38 * *$ & 2.42 & -0.35 & 0.02 \\
Eastbound Trip & $-0.95 * *$ & -2.30 & -1.76 & -0.14 \\
Metro Station & 0.61 & 0.44 & 5.00 & 9.54 \\
Encumbered Passenger & $7.27 * * *$ & 6.29 & 0.33 & 2.12 \\
Signalized Intersection & $1.22 * * *$ & 0.46 & -2.11 & 3.33 \\
Total Boardings*Route 121 & $-0.68 * * *$ & -3.51 & -1.06 & -0.30 \\
Total Boardings*Metro Station & $-0.89 * * *$ & -6.91 & -1.14 & -0.64 \\
\hline$* * *=\mathrm{p}<0.01, * *=\mathrm{p}<0.05, *=\mathrm{p}<0.1$ & & & & \\
Adjusted R-squared: 0.732 & & & & \\
\hline
\end{tabular}

The model results indicate that, on average, each passenger boarding adds 3.2 seconds to the total passenger activity time (door open until end of passenger activity), and each passenger alighting adds 1.1 seconds to the average passenger activity time. Previous research has shown that each passenger boarding adds more time to the overall dwell compared to an alighting passenger. However, in the context of Montreal, boarding times on average are longer than expected, which is attributed to the slower validation process of the smart card system used in Montreal (Diab \& El-Geneidy, 2012a). This is important to consider in this study given that 92 percent of observed passengers paid using a smart card.

The passenger activity squared term, which accounts for the diminishing marginal effects of each additional passenger boarding and alighting on the passenger activity time, behaves consistently with the literature (Diab \& El-Geneidy, 2015; Dueker et al., 2004; El-Geneidy \& Vijayakumar, 2011). Passenger friction was used to capture the effect of an overcrowded bus with standees on passenger activity time (Diab \& El-Geneidy, 2015), and was calculated as the sum of passenger activity and number of standees within one square meter of each door, based on the 
method derived by Dueker et al. (2004). The calculation of the friction variable in this study was based on on-board observations, for other studies to include such variable they can either use archived on-board video recording or on-board observation, in the absence of these methods similar variable can be derived from density of standees and passenger activity obtained from automatic passenger counters or smart card data that requires a tap on and tap off, which will be also building on Dueker et al. (2004) friction variable. While previous literature found that a higher passenger friction factor (i.e. a heavily loaded bus with high passenger activity) increased the dwell time at a bus stop (Dueker et al., 2004; Lin \& Wilson, 1992; Milkovits, 2008), we observe that a higher friction factor decreases the passenger activity time. This may be explained by the increased use of the middle and back doors when the bus is crowded, particularly for passengers alighting. It may also be related to the nature of articulated buses, as previous studies observed regular buses only. Furthermore, passenger load increases passenger activity time, by adding 0.03 seconds per additional passenger on the bus.

Passenger activity time of bus stops along route 121 was on average 1.38 seconds slower than stops along route 69 . This variable should be interpreted with the interaction term and it will be discussed in detail later in the analysis. In the event of an encumbered passenger boarding or alighting the bus, the passenger activity time is increased by 7.3 seconds on average. With respect to passengers with various encumberments or mobility restrictions, if other passengers boarding or alighting were able to do so at alternative doors, this would likely reduce the passenger activity time of bus stops serving encumbered passengers. Delays that result from encumbered passenger boardings often result in a queue of passengers waiting to board at the front doors, who could otherwise use middle or rear doors.

Bus stops located at signalized intersections added 1.2 seconds on average to the passenger activity time, compared to non-signalized or mid-block stops, which is consistent with previous studies finding longer dwell times at stops located at traffic lights (Diab \& El-Geneidy, 2015). This may be because bus stops located at signalized intersections serve more passengers and are where more transfers occur. While other variables such as near-side or far-side stops, bus reserved lane in operation, and right-turn lane were significant predictors of dwell times at bus stops in a previous study (Diab \& El-Geneidy, 2015), these variables did not show statistical significance in our passenger activity time model. This indicates a lack of impact on time required for passenger activity at bus stops, as they generally impact the excess dwell time. 
Regarding the interaction term, Total Boardings*Route 121 showed a statistically significant negative impact on passenger activity time of -0.678 . This variable indicates the impacts of all-door boarding on passenger activity time, however, the interaction term should be interpreted in combination with the total boardings and route 121 variables. To illustrate the results, a sensitivity analysis was conducted. For a stop along route 121 where three passengers boarded the bus, these three passengers need 12.8 seconds. The same passengers along route 69 require 13.5 seconds, showing a five percent savings in passenger activity time when comparing a route with all-door boarding (route 121) to a regular route (route 69). The interaction term for a metro station showed a statistically significant negative impact of -0.891 seconds per boarding passenger. Similarly, interpretation of this coefficient needs to occur with other variables to understand the actual savings from all-door boardings at metro stations. To provide an example, metro stations generally experience an average of five and a half times more boardings. Passenger activity time for 17 passengers to board at a metro station along route 121 is expected to be 43.4 seconds on average compared to an estimate of 53.6 seconds on route 69 . The difference represents time savings of around 19 percent due to the all-door boarding strategy at metro stations. In other words, all-door boarding savings are maximized at stops with high passenger demand, as found in a recent study (Tirachini, 2013). Aggregating these savings to the full cycle of a route that serves 52 stops in one direction and 48 in the other, including two metro stations, the savings can be around two minutes in the full cycle. The full cycle for this route, which includes two 20 minute layovers, is around 140 minutes. Accordingly, the time savings from all-door boarding represents 1.2 percent, which is lower than predictions made in a previous study (C. Stewart \& El-Geneidy, 2014), and will be elaborated on in the discussion section of the manuscript.

While the overall time savings are low, this analysis of the operations data has revealed that all-door boarding systems can result in some passenger activity time savings. Furthermore, while it is important for transit agencies to be operationally efficient, it is also essential to understand the impacts of these savings on the overall satisfaction among existing users. The following section analyses the perceptions, opinions, and characteristics of users on route 121 who have experienced the new all-door boarding service as well as the former single-door boarding service. 


\section{ANALYSIS OF CUSTOMERS' SATISFACTION AND PERCEPTIONS}

The second objective of this study is to measure the satisfaction of passengers currently using route 121 who experienced the implementation of the all-door boarding policy.

\section{The customer satisfaction survey}

Customer satisfaction surveys were administered exclusively along route 121, where all-door boarding had been implemented. Survey collection occurred at the same time as the collection of the operations data. The survey was one page in length, with both French and English language versions, and took respondents approximately three minutes to complete. Surveyors worked in groups of two or three and administered surveys to passengers making both eastbound and westbound trips. To avoid bias in respondent selection, surveyors approached the first passenger to arrive at a bus stop. Surveyors would confirm that the passenger was waiting to use route 121 and that he or she was aware of the all-door boarding policy. If these qualifications were met, surveyors would ask if he or she would like to participate in the survey. Of those who agreed to participate, 75 percent were provided clipboards and pens to self-administer the survey. The remainder of respondents indicated a preference to conduct the survey orally with the surveyor. In order to obtain a representative sample size, stops with a greater number of passengers waiting were prioritized by surveyors. Although this resulted in a modest oversampling at stops intersecting with metro stations, surveys were administered along the entire length of the route. As reported in several other bus surveys (Diab \& El-Geneidy, 2014; Hess, Brown, \& Shoup, 2004; Mishalani, McCord, \& Wirtz, 2006; Psarros, Kepaptsoglou, \& Karlaftis, 2011), many respondents were not able to fully complete the survey, generally because a bus arrived before completing the survey.

Respondents were asked to answer thirteen questions about their usage and experience regarding route 121 . With regard to satisfaction, respondents were asked to rate their experience of using route 121 on a Likert-scale ranging from 1 ('very unsatisfied') to 5 ('very satisfied'), for three aspects of the service: (a) overall satisfaction; (b) on-time arrival; and (c) travel time. Respondents were subsequently asked whether their level of satisfaction had changed since the introduction of the all-door boarding policy for the same three aspects of service and were given the following options: (a) decreased; (b) stayed the same; and (c) increased. Furthermore, respondents were asked questions regarding the characteristics of their trip (e.g.: door used, trip 
purpose, fare type), and their personal characteristics (e.g.: age, sex, car ownership). At the end of the survey, respondents were also given an option to leave comments if interested.

A total of 642 surveys were administered, 192 of which were incomplete, leaving 450 fully completed surveys. Additional surveys were omitted if the respondent indicated they were under the age of 16 or if the respondent indicated that they did not use route 121 before the implementation of the all-door boarding policy. In total, 53 surveys were omitted on this basis leaving 397 surveys included in the analysis. This number exceeds the 380 surveys necessary for a representative sample size, based on the daily passenger activity aboard the route with a confidence interval of $+/-5$ at the $95 \%$ confidence level.

\section{Customer satisfaction survey summary statistics}

A summary of survey responses from the customer satisfaction survey is presented in Table 3, where survey respondents are segmented by whether they boarded at the front door or either the middle or back doors on their most recent trip. A series of t-tests were conducted to determine the statistical significance of the observed differences between segmented groups. In total, 59 percent reported boarding via the middle or back doors on their most recent trip. This group indicated higher overall satisfaction on a five point scale with the current service (4.03) than front door users (3.76). Additionally, passengers using the middle or back door were, on average, approximately four years younger and were significantly more likely to use route 121 five days or more per week. Considering that 81 percent of middle and back door users reported taking route 121 five or more days per week, in contrast to 59 percent of front door users, this indicates the importance of communicating the new service to irregular users. Although the STM implemented a campaign to advertise the new service during the first month of implementation, similar campaigns need to be conducted more frequently to ensure that all users are comfortable boarding through all doors. Finally, 85 percent of front door users had an unlimited pass, which indicates that many front door users were eligible for back-door boarding but either chose not to, or were not aware of the opportunity. 
TABLE 3. Summary statistics from satisfaction survey

\begin{tabular}{|c|c|c|c|c|c|c|}
\hline & \multicolumn{2}{|c|}{ Total population } & \multicolumn{2}{|c|}{ Front door only } & \multicolumn{2}{|c|}{ Middle or back Door } \\
\hline & Mean & $\begin{array}{l}\text { Std. } \\
\text { Dev. }\end{array}$ & Mean & $\begin{array}{l}\text { Std. } \\
\text { Dev. }\end{array}$ & Mean & $\begin{array}{l}\text { Std. } \\
\text { Dev. }\end{array}$ \\
\hline Reported use of mid or back door (\%) & & .49 & 0 & - & 100 & - \\
\hline Travel time decrease $(\%)$ & 54 & .50 & $34 *$ & .48 & $67 *$ & .47 \\
\hline Travel time increase (\%) & 6 & .23 & 9* & .29 & $3 *$ & .18 \\
\hline Overall satisfaction (1-5) & 3.92 & .99 & $3.76^{*}$ & 1.11 & $4.03 *$ & .88 \\
\hline Overall satisfaction increase (\%) & 45 & .50 & $28^{*}$ & .45 & $56^{*}$ & .50 \\
\hline Overall satisfaction decrease (\%) & 7 & .25 & 9 & .28 & 6 & .23 \\
\hline On time satisfaction (1-5) & 3.74 & 1.01 & 3.67 & 1.08 & 3.78 & .97 \\
\hline On time satisfaction increase (\%) & 34 & .47 & $24 *$ & .43 & $41 *$ & .49 \\
\hline On time satisfaction decrease (\%) & 6 & .23 & 7 & .26 & 5 & .21 \\
\hline Travel time satisfaction (1-5) & 3.87 & .98 & $3.71 *$ & 1.09 & $3.97 *$ & .88 \\
\hline Travel time satisfaction increase (\%) & 3 & .48 & $24 *$ & .43 & $44^{*}$ & .50 \\
\hline Travel time satisfaction decrease (\%) & 7 & .25 & 7 & .26 & 6 & .24 \\
\hline Work purpose (\%) & 69 & .47 & $60 *$ & .49 & $75^{*}$ & .44 \\
\hline 2 to 4 days a week (\%) & 22 & .41 & $29 *$ & .45 & $17^{*}$ & .38 \\
\hline 5 days a week or more (\%) & 72 & .45 & $59 *$ & .49 & $81 *$ & .39 \\
\hline Duration of 121 bus use (months) & 67 & 85 & 76 & 92 & 60 & 79 \\
\hline $\begin{array}{l}\text { Passengers with an unlimited pass } \\
(\%)^{1}\end{array}$ & & .29 & $85^{*}$ & .36 & $94 *$ & .23 \\
\hline $\begin{array}{l}\text { Passengers with access to a vehicle } \\
(\%)\end{array}$ & & .50 & 42 & .50 & 46 & .50 \\
\hline Age (year) & 35.8 & 14.62 & $38 *$ & 15.71 & $34.4^{*}$ & 13.66 \\
\hline Intending to use less transit (\%) & 14 & .35 & 17 & .37 & 12 & .33 \\
\hline Intending to use more transit (\%) & 10 & .29 & 12 & .33 & 8 & .27 \\
\hline Number & 397 & & 161 & & 236 & \\
\hline
\end{tabular}

\section{Travel Time}

Of all the passengers included in the analysis, 54 percent reported experiencing shorter travel times since the implementation of the all-door boarding policy. The reported travel time change among front door users and middle and back door users is presented in Figure 2. Note that the total population of respondents in Figure 2 is lower than the total population of respondents in Table 3, as 20 surveys were omitted for outlying responses that had changes in travel time greater than five 
minutes. The majority (67\%) of middle and back door users reported a decrease in travel time of two and a half minutes on average, and 34 percent of front door users reported an average time savings of two minutes. This is an important finding as it shows that users are overestimating the travel time savings compared to the numbers observed in the analysis of the operations data.

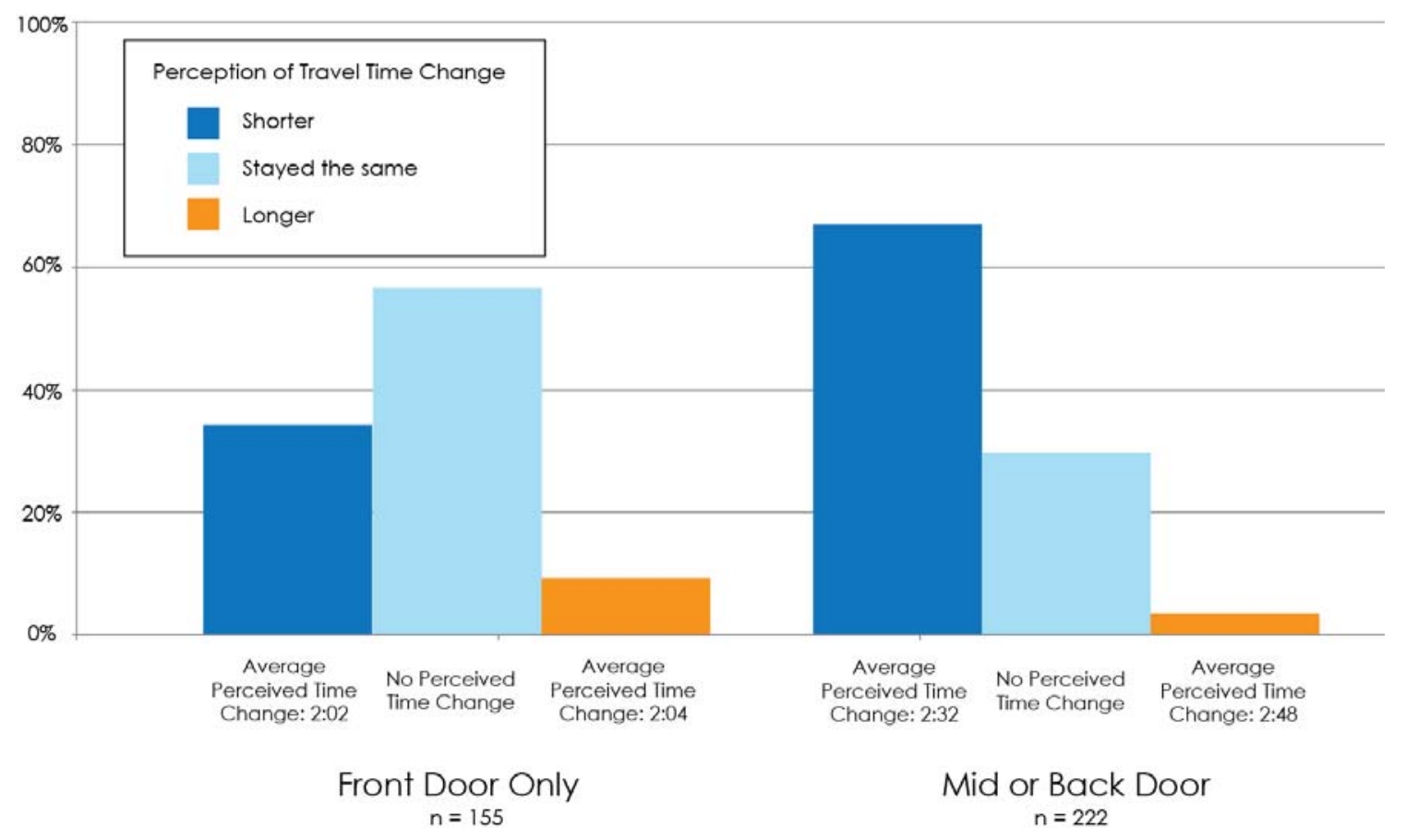

FIGURE 2. Perceived travel time changes among different door users

To further illustrate changes in satisfaction, Figure 3 demonstrates the percentage of respondents who reported increases in travel time satisfaction among different door users. This finding suggests that middle or back door users are more likely to perceive benefits. However, the perceived decreases in travel time among middle or back door users did not always result in increases in satisfaction, as a higher percentage of middle or back door users reported decreases in travel time (67\%) compared to increases in travel time satisfaction (44\%). This will be elaborated on in the discussion of this manuscript.

Overall, given that middle and back door users reported higher levels of satisfaction with travel time, this finding suggests that these users are more receptive to improvements in service, which means that small changes in operations can have a large impact on customers who benefit from the change. 


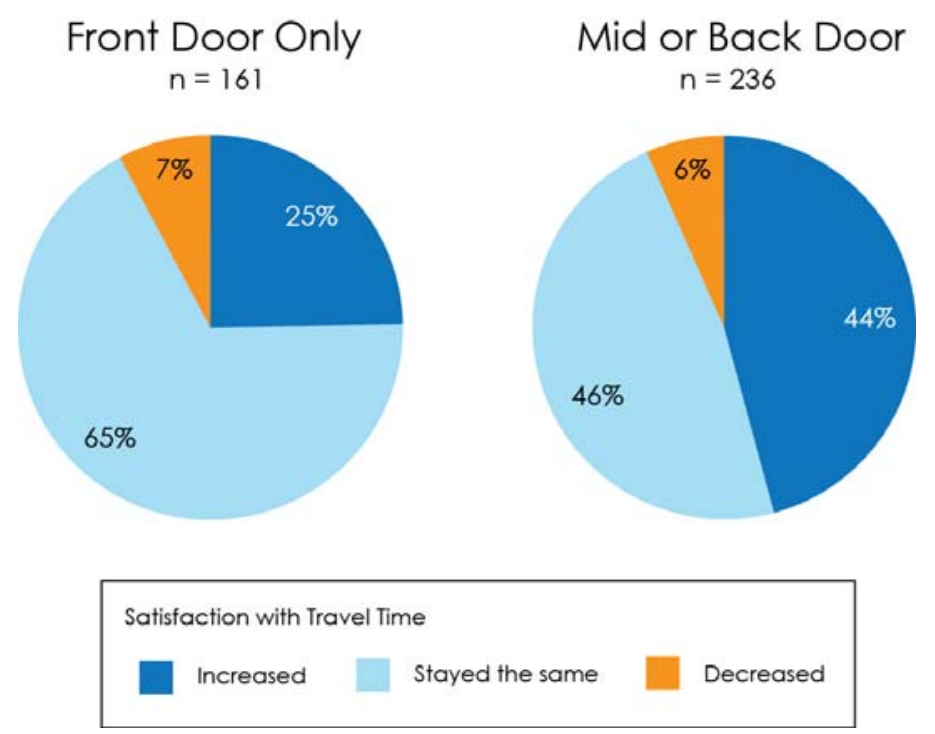

FIGURE 3. Reported rates of increases in satisfaction among different door users

\section{FURTHER OBSERVATIONS}

In addition to analyzing changes in service operation and customer satisfaction, qualitative observations were collected from all surveyors. Observations were documented while talking to bus drivers and users and through monitoring passenger activity time on the bus. It is important to note, that in general, users were positive about their experience with route 121 after the implementation of all-door boarding, namely with the frequency and reliability of the route.

One important and consistent observation was that the drivers did not always open the middle and back doors to encourage boarding through all doors. This observation was echoed by passengers, who expressed frustration with the inconsistency of drivers opening all doors. Consequently, passengers reported that they could not always rely on all-door boarding as a consistent service, which in turn could decrease their likelihood of waiting for a middle or back door in the future. This partially explains the lower percentage of people who indicated an increase in satisfaction among back door users when compared to those who observed time savings.

A lack of communication around the implementation of all-door boarding seemed to be experienced both by passengers and drivers. Bus drivers indicated that they had not been instructed to open all doors at all stops. Users were seemingly confused about how the new all-door boarding service was intended to function. The summary statistics revealed that the majority of users who boarded at the front door had unlimited use passes, which do not require on-board validation. This 
means that the reduced boarding times that are possible when users activate payment prior to boarding were not being achieved (Jara-Diaz \& Tirachini, 2013).

In addition, several passengers reported that they believed that those using the middle and back doors were boarding the bus without paying, causing frustration among users who felt that these people were acting unfairly. Furthermore, during the observation period there were no representatives of the transit agency verifying fares or encouraging passengers to board through the rear doors. However, previous studies found that fare evasion is usually lower than it is perceived to be (Larwin \& Koprowski, 2012; Lee, 2011). Therefore, fare evasion is not expected to be problematic for the implementation of all-door boarding on route 121. These findings suggest that it is important for the transit agency, STM in this case, to continue communicating the alldoor boarding service to passengers beyond the first month of implementation as our findings reveal that not all users were aware of the service.

Another observation made by surveyors is that, at stops with high user activity, users organized themselves into separate lines for each door while waiting for the 121. This worked especially well in locations where there was a large platform for passengers to wait and lines had been painted on the ground to indicate where the doors would be when the bus arrived.

A final observation was the amount of excess dwell time, especially at bus stops serving metro stations. Buses would often stand at the station for several minutes after all the passengers had boarded with the door open. This excess dwell caused any time gains from quicker boarding to be lost through long dwell times. Accordingly, the 121 is not currently reaching the time savings predicted by C. Stewart and El-Geneidy (2014) with this excess dwell time. This finding suggests that additional modifications to the schedules are needed as the drivers were operating these buses ahead of schedule.

\section{DISCUSSION \& CONCLUSION}

Using both quantitative and qualitative measures, this study has revealed the operational and customer satisfaction benefits of implementing an all-door boarding system. The results of the passenger activity time model revealed moderate time savings associated with the service (1.2\% time savings for the overall route cycle time). These findings are lower than previous research which forecasted a time savings from the implementation of all-door boarding along route 121 (C. Stewart \& El-Geneidy, 2014). These authors predicted time savings of 3.3 percent of the route 
cycle time based on an all-door boarding system implemented at major stops along the route. This difference is likely because the estimated time savings predicted by C. Stewart and El-Geneidy (2014) were based on the assumption that passengers would board equally between the three doors. However, our operational data showed that the average boarding rate for the front, middle and back door was 88 percent, 6.4 percent and 5.6 percent respectively, when considering stops where three or more passengers boarded, and multiple doors could have been used. The lower than anticipated time savings observed in our study is therefore likely because the majority of boardings occurred through the front-door. If boardings were distributed equally, STM could experience higher time savings. Furthermore, passengers should be encouraged to alight the bus at the back doors for a smoother flow of passenger activity and to make space for passengers who need to board through the front doors in order to validate tickets. Our study therefore highlights the importance of effective communication strategies to achieve the maximum potential time savings of an all-door boarding policy.

Another reason that the time savings were lower than predicted is because, while the model results indicate a modest time savings at regular passenger activity stops $(5 \%)$, significantly higher time savings at metro stations (19\%) were observed. A sensitivity analysis was used to estimate the time savings from bus stops with varying levels of passenger demand using the passenger activity time model. The findings show that for a similar bus route with an average passenger boarding of five riders per stop along the route, time savings of 2.7 percent of the route cycle time are expected. Furthermore, time savings of 5 percent of the route cycle time are expected for bus routes serving eight passengers on average at each stop. Therefore, while we do see time savings attributable to all-door boarding, substantial time savings can be expected on bus routes with consistently high passenger activity along the entire route. Accordingly, public transit agencies should be more strategic when selecting appropriate bus routes for the implementation of an alldoor boarding system in order to benefit from savings in operating costs. Routes similar to route 121 , but with an average of 3 passengers per regular stop, are expected to show time savings in the range of 1.5 to 3 percent.

While the operational benefits associated with the implementation of the all-door boarding service were modest, this study found that users' perceptions of the service were positive, with many passengers stating that their overall travel time decreased and that their satisfaction increased. Satisfaction for middle and back door users was found to be higher than front door users, 
demonstrating that they were receptive to the service improvements. The increases in satisfaction are positive, and demonstrate that a small operational change can have an important impact on increasing customer satisfaction. This is in line with previous research which has found that users who have a positive image of public transport tend to be more satisfied (Minser \& Webb, 2010) and loyal (Lai \& Chen, 2011; Minser \& Webb, 2010; Şimşekoğlu, Nordfjærn, \& Rundmo, 2015; Zhao, Webb, \& Shah, 2014).

While the implementation of the all-door boarding service had a positive effect on both operations and customer satisfaction, the qualitative observations made on the street, on the bus and by talking to drivers and users indicated that there was a lack of effective communication during the implementation of all-door boarding for the 121 bus route. This resulted in a discrepancy between what users expected and what was provided, and revealed the fact that there was an unawareness of how the all-door boarding service is intended to function. Furthermore, the time gained through line formation and more efficient boarding was lost as a result of excess dwell times, meaning that the 121 is not currently maximizing the potential of all-door boarding. Schedule readjustments are thus needed to fully maximize the benefits of implementing the alldoor boarding service, and boarding times and dwell times could be decreased further by allowing all passengers with activated tickets to board through any of the doors. Additionally, greater communication to customers of the all-door boarding system and more encouragement for drivers to open all doors and for passengers to use all doors while boarding will likely improve the effectiveness of the service change. Overall, the results of this study have demonstrated that alldoor boarding is an effective strategy to improve the quality of service due to the associated time savings and increased customer satisfaction. These findings are generalizable and applicable to different boarding and alighting payment schemes, including tap-on and tap-off systems as well as off-board fare payment systems. Furthermore, as this was a pilot project, it is expected that introducing all-door boarding along successive bus routes will increase customer familiarity with the service, which in turn will positively influence the operational time savings and overall satisfaction of bus users.

\section{ACKNOWLEGEMENTS}

We would like to acknowledge the financial support received from the Social Sciences and Humanities Research Council (SSHRC) and the Natural Sciences and Engineering Research 
Council of Canada (NSERC). We would also like to thank the surveyors who helped collect the data, as well as all of the users of route 121 Sauvé who took the time to participate in the study. Lastly, we would like to thank the anonymous reviewers for their invaluable input on the paper.

\section{REFERENCES}

Abkowitz, M., \& Engelstein, I. (1982). Factors affecting running time on transit routes. Transportation Research, $17(2), 6$.

Berkow, M., El-Geneidy, A., Bertini, R., \& Crout, D. (2009). Beyond generating transit performance measures: Visualizations and statistical analysis with historical data. Transportation Research Record(2111), 158-168.

Bonfanti, G., \& Wagenknecht, T. (2010). Human factors reduce aggression and fare evasion. Public Transport International, 59(1).

Cundill, M., \& Watts, P. (1973). Bus boarding and alighting times: Transport and Road Research Laboratory.

dell'Olio, L., Ibeas, A., \& Cecín, P. (2011). The quality of service desired by public transport users. Transport Policy, 18(1), 217-227.

Diab, E., \& El-Geneidy, A. (2012a). Understanding the impacts of a combination of service improvement strategies on bus running time and passenger's perception. Transportation Research Part A: Policy and Practice, 46(3), 614-625.

Diab, E., \& El-Geneidy, A. (2012b). Understanding the impacts of a combination of service improvement strategies on bus running time and passengers' perceptions. Transportation Research Part A: Policy and Practice, 46(3), 614-625.

Diab, E., \& El-Geneidy, A. (2014). Transitory optimism: Changes in passenger perception following bus service improvement over time. Transportation Research Record, 2415, 97-106.

Diab, E., \& El-Geneidy, A. (2015). The far side story: Measuring the benefits of bus stop location on transit performance. Transportation Research Record, 2538, 1-10.

Dueker, K., Kimpel, T., Strathman, J., \& Callas, S. (2004). Determinants of bus dwell time. Journal of Public Transportation, 7(1), 2.

El-Geneidy, A., Strathman, J., Kimpel, T., \& Crout, D. (2006). The effects of bus stop consolidation on passenger activity and transit operations. Transportation Research Record, 1971, 32-41.

El-Geneidy, A., \& Vijayakumar, N. (2011). The effects of articulated buses on dwell and running times. Journal of Public Transportation, 14(3), 4.

Fernandez, R. (2011). Experimental study of bus boarding and alighting times. Paper presented at the European Transport Conference, Glasgow.

Gibson, J., Munizaga, M., Schneider, C., \& Tirachini, A. (2015). Estimating the bus user time benefits of implementing a median busway: Methodology and case study. Transportation Research Part A: Policy and Practice.

Hess, D., Brown, J., \& Shoup, D. (2004). Waiting for the bus. Journal of Public Transportation, 7(4), 67-84.

Jaiswal, S., Bunker, J., \& Ferreira, L. (2010). Influence of platform walking on BRT station bus dwell time estimation: Australian analysis. Journal of Transportation Engineering, 136, 6. doi: 10.1061/ ASCE TE.19435436.0000174

Jara-Diaz, S., \& Tirachini, A. (2013). Open all doors for boarding. Journal of Transport Economics and Policy, 47(1), 15.

Kimpel, T. (2001). Time point-level analysis of transit service reliability and passenger demand. (Doctor of Philosophy), Portland State University, Portland.

Kimpel, T., Strathman, J., Bertini, R., Bender, P., \& Callas, S. (2005). Analysis of transit signal priority using archived TriMet bus dispatch system data. Transportation Research Record, 1925(156-166).

Lai, W., \& Chen, C. (2011). Behavioral intentions of public transit passengers-The roles of service quality, perceived value, satisfaction and involvement. Transport Policy, 18(2), 318-325.

Larwin, T., \& Koprowski, Y. (2012). Off-board fare payment using proof-of-payment verification. Washington: Transportation Research Board.

Lee, J. (2011). Uncovering San Francisco, California, muni's proof-of-payment patterns to help reduce fare evasion. Transportation Research Record: Journal of the Transportation Research Board, 2216, 9. 
Levine, J., \& Torng, G. (1994). Dwell time effects of low-floor bus design. Journal of Transportation Engineering, 120(6), 829-914.

Levinson, H. (1983). Analyzing transit travel time performance. Transportation Research Record, 915, 1-6.

Levinson, H., Zimmerman, S., Clinger, J., \& Rutherford, G. (2002). Bus rapid transit: An overview. Journal of Public Transportation, 5(2), 1-30.

Lin, T., \& Wilson, N. (1992). Dwell time relationships for light rail systems. Transportation Research Record(1361), 287-205.

Milkovits, M. (2008). Modeling the factors affecting bus stop dwell time: Use of automatic passenger counting, automatic fare counting, and automatic vehicle location data. Transportation Research Record, 2072, 125130.

Minser, J., \& Webb, V. (2010). Quantifying the Benefits: Application of customer loyalty modeling in public transportation context. Transportation Research Record: Journal of the Transportation Research Board, 2144(1), 111-120.

Mishalani, R., McCord, M., \& Wirtz, J. (2006). Passenger wait time perceptions at bus stops: Empirical results and impact on evaluating real-time bus arrival information. Journal of Public Transportation, 9(2), 89-106.

Mouwen, A. (2015). Drivers of customer satisfaction with public transport services. Transportation Research Part A: Policy and Practice, 78, 1-20.

Psarros, I., Kepaptsoglou, K., \& Karlaftis, M. (2011). An empirical investigation of passenger wait time perceptions. Journal of Public Transportation, 14(3), 109-122.

Rajbhandari, R., Chien, S., \& Daniel, J. (2003). Estimation of bus dwell time with automatic passenger counter information. Transportation Research Record, 1841, 120-127.

Şimşekoğlu, Ö., Nordfjærn, T., \& Rundmo, T. (2015). The role of attitudes, transport priorities, and car use habit for travel mode use and intentions to use public transportation in an urban Norwegian public. Transport Policy, 42, 113-120.

Stewart, A., Attanucci, J., \& Wilson, N. (2015). Ridership response to incremental Bus Rapid Transit upgrades in North America: Demographic and network effects. Transportation Research Record: Journal of the Transportation Research Board, 2538, 37-43.

Stewart, C., \& El-Geneidy, A. (2014). All aboard at all doors: Route selection and running-time savings estimation for multiscenario all-door bus boarding. Transportation Research Record: Journal of the Transportation Research Board(2418), 39-48.

Strathman, J., Dueker, K., Kimpel, T., Gerhart, R., Turner, K., Taylor, P., . . Griffin, D. (2000). Service reliability impacts of computer-aided dispatching and automatic vehicle location technology: A Tri-Met case study. Transportation Quarterly, 54(3), 85-102.

Sun, L., Tirachini, A., Axhausen, K., Erath, A., \& Lee, D. (2014). Models of bus boarding and alighting dynamics. Transportation Research Part A: Policy and Practice, 69, 447-460.

Tirachini, A. (2013). Estimation of travel time and the benefits of upgrading the fare payment technology in urban bus services. Transportation Research Part C: Emerging Technologies, 30, 239-256.

Tirachini, A., Camus, L., \& Cruz, D. (2016). Modelación de tiempos de detención de buses en paraderos de Santiago y Valparaíso-Viña del Mar. Ingeniería de Transporte, 19(2).

Vandebona, U., \& Richardson, A. (1985). The effects of fare-collection strategies on transit level of service. Transportation Research Record(1036).

Walker, J. (2012). Human transit: How clearer thinking about public transit can enrich our communities and our lives. Washington, DC: Island Press.

Zhao, J., Webb, V., \& Shah, P. (2014). Customer loyalty differences between captive and choice transit riders. Transportation Research Record: Journal of the Transportation Research Board(2415), 80-88. 